\title{
Trigeminal Neuralgia: Report of a Case and Literature Review
}

\author{
Sadat SMA ${ }^{1}$, Sultana $\mathrm{A}^{2}$, Rita $\mathrm{SN}^{3}$, Khan $\mathrm{MR}^{4}$
}

\begin{abstract}
Trigeminal neuralgia is a sudden, severe, stabbing, recurrent and usually unilateral pain in the distribution of one or more branches of the fifth cranial nerve. A 55 years old man, diagnosed case of Trigeminal Neuralgia of the left side of the face was treated with oral carbamazepine with good response. But after that the disease became refractory to the drug. With the titration of dose of carbamazepine, raising up to $1200 \mathrm{mg}$ daily in three equal divided doses added with amitryptylene, we could give relief of pain to patient. The patient is now under observation \& we are following him for last 6 months with a good response of the combination drug. It justifies that alteration, titration of carbamazepine and combination with amitryptylene can cause remission of trigeminal neuralgia instead of doing surgical intervention.
\end{abstract}

Keywords: Carbamazepine, Trigeminal Neuralgia

\section{Introduction}

Trigeminal neuralgia is a sudden, severe, stabbing, recurrent and usually unilateral pain in the distribution of one or more branches of the fifth cranial nerve. Some patients may have a background dull aching pain after the main attack. It is seen more in women than men and affects usually between the fifth and eighth decade of life ${ }^{1}$. Trigeminal Neuralgia occurs more frequently in the second and third divisions of the trigeminal nerve. It is also characterized by regions of increased arousal, called trigger zones. The attack is sometimes associated with salivation, lacrimation, rhinorrhea, nasal mucosa congestion and skin redness.

In trigeminal neuralgia, the myelin sheath around the nerves disappear over time due to degenerative processes of aging and vascular compression acting for years about the root of the trigeminal nerve ${ }^{2}$. TN may also be related to incorrect surgery of oral and maxillofacial trauma ${ }^{3}$. Proper history with meticulous clinical examination with imaging studies is necessary to exclude other causes of facial pain and thus

1. Corresponding Author : Dr. S. M. Anwar Sadat BDS, BCS, MCPS, FCPS, MS (OMS), Resident Surgeon Department of Oral \& Maxillofacial Surgery Dhaka Dental College Hospital, Dhaka e-mail: an_sadat@yahoo.com

2. Dr. Afia Sultana, BDS, PGT (Oral Surgery) Honorary Medical Officer Department of Oral \& Maxillofacial Surgery Dhaka Dental College Hospital, Dhaka

3. Dr. Sufia Nasrin Rita, BDS, FCPS (Orthodontics) Associate Professor \& Head Department of Orthodontics Sapporo Dental College Hospital

4. Dr. Md. Raziuddin Khan, BDS, DDS Associate Professor. Department of Anatomy Dhaka Dental College, Dhaka diagnosis of trigeminal neuralgia. Nurmikko and Eldridge proposed three types of trigeminal neuralgia: typical, atypical and trigeminal neuropathy ${ }^{4}$. A distinction is made between classical trigeminal neuralgia where the etiology is unknown or due to vascular compression as compared with symptomatic trigeminal neuralgia was the trigeminal neuralgia is secondary to a tumor, MS or a structural abnormality of the skull base.

$\mathrm{TN}$ is treated by both conservative and surgical approaches ${ }^{5}$, Medical therapy is usually considered first and functional neurosurgery is done only in case where clinical therapy proves ineffective ${ }^{6}$. Drug treatment is the use of anticonvulsants, centrally acting muscle relaxants, neuroleptics and local anesthetics. Surgical treatment aims to interruption of peripheral trigeminal pathways or the elimination of possible causes ${ }^{7}$.

Many trials of treatment for trigeminal neuralgia do not state the diagnostic criteria used, do not have robust outcome measures and so may account for the variations in results. There are relatively few large high quality randomized controlled trials of medical management in trigeminal neuralgia and their design is so variable that meta-analysis is virtually impossible. There is, therefore, a need for some future guidelines for the conduct of randomized controlled trials (RCT) in trigeminal neuralgia. The aim of this study was to present a case of trigeminal neuralgia which responded well with conservative approach though initially was refractory. The review provides some evidence based guidance on medical management of trigeminal neuralgia and also to put forward some recommendations of how to design trials in the future.

\section{Case Report}

A 55 years old man, hailing from Bogura, with diagnosed case of Trigeminal Neuralgia of the left side of the face, reported to the department of Oral \& Maxillofacial Surgery, Dhaka Dental College Hospital on September 2013. Patient had been getting treatment of the classic form of the disease with conventional medications (Tegretol 200mg twice daily) by a local doctor for the last 11 years. The patient's initial complain was pain on the left side of the lower face which was sharp, shooting, lancinating type started mainly during taking food or washing face. Initially the pain lasted for few seconds with gradually increasing in duration \& frequency of attack. Then he was treated with oral carbamazepine with an initial divided dose of $200 \mathrm{mg}$ daily which was gradually increased to $600 \mathrm{mg}$ in three divided doses within 6 months period. With good response to the prescribed medications patient was well for two years. The initial response to the drug was good but caused weakness, drowsiness, dizziness and so patient himself used to discontinue the medication occasionally. After two years, pain reappeared with nonresponsiveness of the drug. The frequency of pain increased and gradually distributed to mid face and upper face with three years period. Then the attending physician increased the dose up to $800 \mathrm{mg} /$ day in three divided doses with a combination 
of vitamin B12 \& vitamin B6. The drug worked for 7 more years with adjustment of doses at a regular interval. But after that the disease became refractory to Tegretol. The patient then took Gabapentin for another 2 years with the dose of $300 \mathrm{mg}$ twice daily which also failed to give remission to the patient. Then patient came to our hospital for better treatment. Hematological profiles and liver function tests were normal. Orthopantomogram and paranasal view radiograph were done to exclude other possibilities of pain. Magnetic Resonance Imaging or Magnetic Resonance Angiogram could not be done due to financial constraint though these were necessary to identify any intra cranial causes of trigeminal neuralgia. Considering patient's age, body built, physical condition, we again started carbamazepine with initial dose of $600 \mathrm{mg} /$ day along with an anti-depressant drug (amitryptylene $10 \mathrm{mg}$ once daily) instead of surgical intervention. With the titration of doses raising up to $1200 \mathrm{mg}$ daily in three equal divided doses we could give relief of pain to patient. The patient is now under observation \& we are following him for last 6 months with a good response with carbamazepine and amitryptylene in above mentioned doses. It justifies that alteration, titration of carbamazepine and combination with amitryptylene can cause remission of trigeminal neuralgia instead of doing surgical intervention.

\section{Discussion}

Diagnosis of Trigeminal Neuralgia is mostly by history and clinical findings. It presents with sudden and severe lancinating pain usually lasts few seconds to minutes, within the distribution of trigeminal nerve, mostly the mandibular or maxillary branches. Pain is often evoked by trivial stimulation in the "trigger zones."

Sometimes the pain is so severe and aggravated by talking, drinking, eating, tooth brushing or face washing. The nerves affected are usually stereotyped for a particular patient and lie within the sensory distribution of the trigeminal nerve.

\section{Diagnostic criteria for classic trigeminal neuralgia ${ }^{8}$}

- Sudden and severe lancinating pain which is aroxysmal in nature

- Pain lasts fraction of a second to minutes that affect one or more divisions of the trigeminal nerve

- Pain has at least one of the following characteristics intense, sharp, superficial, or stabbing precipitated from trigger areas or by trigger factors

- Attacks are similar in individual patients

- No neurological deficit is clinically evident

- Not attributed to another disorder

Sometimes pain of trigeminal neuralgia does not fit the usual criteria exactly because of a persistent ache between paroxysms or mild sensory loss. Such disease is known as "atypical" or "mixed" trigeminal neuralgia ${ }^{10}$. Patients with atypical disease are more likely to have symptomatic rather than idiopathic disease, and they are often more refractory to treatment ${ }^{10}$ than those with classic trigeminal neuralgia ${ }^{11}$. Atypical trigeminal neuralgia should not be confused with atypical facial pain (table 1). Other causes of facial pain are much more common than trigeminal neuralgia. This can often lead to delay in diagnosis as patients see dentists and doctors who consider more common alternatives first.
Diagnosis of common causes of facial pain are usually straightforward to eliminate clinically or after dental examination (table 1). In some occasions, pain affects the forehead only, which is rare for trigeminal neuralgia, so trigeminal neuralgia affecting the forehead should be diagnosed with caution. Although tearing and other autonomic features can occur in trigeminal neuralgia, these features combined with forehead pain should prompt consideration of the trigeminal autonomic cephalalgias or cluster headache ${ }^{8}$.

Table 1 Common conditions that are usually easy to distinguish from Trigeminal Neuralgia ${ }^{8,12,13}$

\begin{tabular}{ll}
\hline \multicolumn{1}{c}{ Diagnosis } & \multicolumn{1}{c}{ Important features } \\
\hline $\begin{array}{l}\text { Dental infection or } \\
\text { cracked tooth }\end{array}$ & $\begin{array}{l}\text { Well localised to tooth; local swelling and } \\
\text { erythema; appropriate findings on dental } \\
\text { examination }\end{array}$ \\
$\begin{array}{l}\text { Temporomandibular } \\
\text { joint pain }\end{array}$ & $\begin{array}{l}\text { Often bilateral and may radiate around } \\
\text { ear and to neck and temples; jaw opening } \\
\text { may be limited and can produce an audible } \\
\text { click }\end{array}$ \\
$\begin{array}{l}\text { Persistent idiopathic } \\
\text { facial pain } \\
\text { (previously "atypical }\end{array}$ & $\begin{array}{l}\text { Often bilateral and may extend out of } \\
\text { trigeminal territory; pain often continuous, } \\
\text { facial pain") }\end{array}$ \\
migraine & $\begin{array}{l}\text { throbbing in character } \\
\text { Often preceded by aura; severe unilateral } \\
\text { headache often associated with nausea, } \\
\text { photophobia, phonophobia, and neck } \\
\text { stiffness }\end{array}$ \\
& $\begin{array}{l}\text { Common in elderly people; temporal pain } \\
\text { should be constant and often associated } \\
\text { with jaw claudication, fever, and weight }\end{array}$ \\
& $\begin{array}{l}\text { loss; temporal arteries may be firm, tender, } \\
\text { and non-pulsatile on examination }\end{array}$ \\
&
\end{tabular}

The treatment of trigeminal neuralgia may be medical or surgical ${ }^{14}$. The medical therapy is the first choice, resorting to the functional neurosurgery only in cases where clinical therapy proves ineffective ${ }^{15}$.

At first, carbamazepine and oxcarbazepin drugs must be administered at lower doses, but if necessary, doses may be increased gradually ${ }^{14}$ as we practiced in our case. Among the surgical procedures most widely used are neurovascular decompression as the primary ablative technique, the radiofrequency rhizotomy, balloon compression and glycerol rhizotomy and radiosurgery ${ }^{16}$. only $25 \%$ of patients present with TN total pain control only with the use of drugs over time $^{17}$. The drugs most commonly used are: local anesthetics, neuroleptics, muscle relaxants, and anticonvulsants. A summary of results of clinical trials / controlled clinical trials of drug treatment of Trigeminal Neuralgia shows the practice of managing trigeminal neuralgia ${ }^{18}$.

Surgical treatment is based on the assumption that the cause is of peripheral origin, such as trigeminal nerve damage in a blood vessel, by a tumor or an inflammatory lesion ${ }^{19}$ In recent years, the two most common procedures used were: a differential percutaneous electrocoagulation of the trigeminal nerve and trigeminal vascular decompression and also with radiofrequency thermocoagulation of the Gasser ganglion an effective method, widely used in patients over 50 years $^{20}$. 
Table2: Summary of results of clinical trials / controlled clinical trials of drug treatment of Trigeminal Neuralgia ${ }^{18}$

\begin{tabular}{|c|c|c|c|}
\hline Study & Drugs used & $\begin{array}{c}\text { Total } \\
\text { no of } \\
\text { patients } \\
\end{array}$ & $\begin{array}{c}\text { Total no } \\
\text { of patients } \\
\text { benefitted (\%) } \\
\end{array}$ \\
\hline Tomson 1981) & CBZ & 8 & 100 \\
\hline Farago (1987) & $\begin{array}{l}\text { CBZ analogues: } \\
\text { (i) Dihydroketo } \\
\text { (ii) Dihydromono- } \\
\text { hydroxy }\end{array}$ & $\begin{array}{l}13 \\
11\end{array}$ & 100 \\
\hline Liebel (2001) & $\begin{array}{l}\text { Oxcarbazepine and } \\
\text { CBZ }\end{array}$ & 48 & $\begin{array}{c}100 \\
\text { (oxcarbazepine) } \\
95(\mathrm{CBZ})\end{array}$ \\
\hline $\begin{array}{l}\text { Zakrzewska et } \\
\text { al (2002) }\end{array}$ & Oxcarbazepine & 15 & $\begin{array}{l}100 \text { Benefited } \\
\text { initially } \\
80 \text { required } \\
\text { surgery }\end{array}$ \\
\hline $\begin{array}{l}\text { Lindstrom } \\
\text { (1987) }\end{array}$ & Tocainide and CBZ & 12 & - \\
\hline $\begin{array}{l}\text { Lechin et al } \\
\text { (1989) }\end{array}$ & Pimozide and CBZ & 48 & $\begin{array}{c}100 \text { (pimozide) } \\
56(\mathrm{CBZ})\end{array}$ \\
\hline $\begin{array}{l}\text { Vilming } \\
(1986)\end{array}$ & $\begin{array}{l}\text { Tizanidine } \\
\text { CBZ }\end{array}$ & $\begin{array}{l}6 \\
6\end{array}$ & $\begin{array}{c}\text { Effects of } \\
\text { tizanidine } \\
\text { Inferior to CBZ }\end{array}$ \\
\hline Merren (1998) & Gabapentin & 60 & 65 \\
\hline $\begin{array}{l}\text { Delvaux et al } \\
\text { (2001) }\end{array}$ & Lamotrigen & 25 & 100 \\
\hline $\begin{array}{l}\text { Steardo et al } \\
\text { (1984) }\end{array}$ & Baclofen & 25 & 68.61 \\
\hline Fromm (1984) & Baclofen & 60 & 30 \\
\hline Parmar (1989) & Baclofen & 20 & 65 \\
\hline $\begin{array}{l}\text { From et al } \\
\text { (1987) }\end{array}$ & $\begin{array}{l}\text { L-Baclofen and } \\
\text { racemic baclofen }\end{array}$ & 9 & 66.6 \\
\hline
\end{tabular}

Abbreviation: CBZ, carbamazepine.

The decompression technique that is considered to promote relief for a longer time, with control of pain by more than $70 \%$ of patients over 10 years ${ }^{20}$. The decompression is indicated in young individuals who want to preserve the facial sensitivity, when there is suspected lesion towards trigeminal neuralgia or when this is combined with other facial neuralgia or hemifacial spasm.

\section{References}

1. Goto F, Ishizaki K, Yoshikawa D, Obata H, Arii H, Terada M. The long lasting effects of peripheral nerve blocks for trigeminal neuralgia using a high concentration of tetracaine dissolved in bupivacaine. Pain, 1999;79:101103.

2. Turp JC, Gobetti JP. Trigeminal neuralgia versus atypical facial pain: a review of the literature and case report. Oral Surgery, Oral Medicine, Oral Pathology, Oral Radiology, 1996;81:424-432.

3. Frizzo HM, Hasse PN. Veronese RM. Neuralgia do Trigêmeo: Revisão Bibliográfica Analítica. Revista de Cirurgia e Traumatologia Buco-Maxilo-Facial, 2004;4:212-217.
4. Nurmikko TJ, Eldridge PR. Trigeminal neuralgia: pathophysiology, diagnosis and current treatment. BJA: British Journal of Anaesthesia, 2001;87:117-132.

5. Quesada GAT, Baptista CE, Daiana SP, Douglas LF. Neuralgia Trigeminal - do diagnóstico ao tratamento. Revista Dentística, 2005;11.

6. Mattos JMB, Bueno FV, Mattos LR. Neuralgia do Trigêmeo: Um novo protocolo de tratamento clínico. Revista Dor, 2005;6:652-656

7. Brow JA. Percutaneous balloon compression for trigeminal Neuralgia. Clinical Neurosurgery, 2009;56:73-76.

8. Headache Classification Subcommitee of the International Headache Society. The international classification of headache disorders. 2nd edition. Cephalalgia 2004;24:1-150.

9. Nurmikko TJ, Eldridge PR. Trigeminal neuralgiapathophysiology, diagnosis and current treatment. $\mathrm{Br} \mathrm{J}$ Anaesth 2001;87:117-32.

10. Zakrzewska JM, Jassim S, Bulman JS. A prospective, longitudinal study on patients with trigeminal neuralgia who underwent radiofrequency thermocoagulation of the Gasserian ganglion. Pain 1999;79:51-8.

11. Lopez BC, Hamlyn PJ, Zakrzewska JM. Systematic review of ablative neurosurgical techniques for the treatment of trigeminal neuralgia. Neurosurgery 2004;54:973-82.

12. Zakrzewska JM. Facial pain: neurological and non-neurological. J Neurol Neurosurg Psychiatry 2002;72(suppl 2):ii27-32.

13. Zakrzewska JM. Diagnosis and differential diagnosis of trigeminal neuralgia. Clin J Pain 2002;18:14-21.

14. Quesada GAT, Baptista CE, Daiana SP, Douglas LF. Neuralgia Trigeminal - do diagnóstico ao tratamento. Revista Dentística, 2005,

15. Mattos JMB, Bueno FV, Mattos LR. Neuralgia do Trigêmeo: Um novo protocolo de tratamento clínico. Revista Dor, 2005, 6, 652-656.

16. Siqueira SRDT, Nobrega JCM, Valle LBS, Teixeira MJ, Siqueira JTT. Idiopathic trigeminal neuralgia: Clinical aspects and dental procedures. Oral Surgery, Oral Medicine, Oral Pathology, Oral Radiology, 2004;98:311-315.

17. Patterson $\mathrm{CW}$. Trigeminal neuralgia $-\mathrm{a}$ dental diagnosis challenge. Northwest Dentistry, 1999:78: 19-24.

18. Chole et al. Drug Treatment of Trigeminal Neuralgia. J Oral Maxillofac Surg 2007.

19. Maestri JM. and Holzer F. Fisiopatología de la neuralgia del trigémeno. Revista Chilena de Neuro-Psiquiatria, 1993;31: 317-321

20. Frizzo HM, Hasse PN. Veronese RM. Neuralgia do Trigêmeo: Revisão Bibliográfica Analítica. Revista de Cirurgia e Traumatologia Buco-Maxilo-Facial, 2004;4:212-217. 